\title{
Equity, intercultural approaches, and access to information on traditional, complementary, and integrative medicines in the Americas*
}

\author{
Daniel F. Gallego-Pérez¹, Carmen Verônica Mendes Abdala², Daniel Miele Amado³, Islândia Maria \\ Carvalho de Sousa ${ }^{4}$, Natalia Sofía Aldana-Martínez ${ }^{5}$ and Ricardo Ghelman ${ }^{6}$
}

Suggested citation Gallego-Pérez DF, Abdala CVM, Amado DM, Carvalho de Sousa IM, Aldana-Martínez NS, Ghelman R. Equity, intercultural approaches, and access to information on traditional, complementary, and integrative medicines in the Americas. Rev Panam Salud Publica. 2021;45:e82. https://doi.org/10.26633/RPSP.2021.82

\begin{abstract}
Access to information and intercultural approaches in the field of health are essential for the elimination of inequities in health access and care. Intercultural models such as traditional, complementary, and integrative medicine (TCIM) are an important part of health care in most countries and often contribute to expanding access to primary health care. Despite legal recognition and policies to integrate TCIM into health systems, their contribution to health, well-being, and people-centered care to achieve universal health is still underestimated. This article presents the progress (2017-2020) achieved by the Virtual Health Library specialized in the TCIM (VHL TCIM Americas), an initiative created as a tool to reduce the gaps in the production and access to validated information on TCIM. Through collaborative network work, VHL TCIM Americas contributes to the democratization of health, access to verified scientific data, visibility of non-conventional knowledge, strengthening of research capacities, and exchange of experiences for informed decision-making.
\end{abstract}

Keywords Medicine, traditional; complementary therapies; comprehensive health care; health equity; access to information; libraries, digital.

Among other transformations aimed at bridging health gaps between populations, addressing health-related inequities involves creating conditions for the self-determination of human groups and individuals. To eliminate health inequities for indigenous peoples, Afro-descendants, and members of other ethnic groups, it is essential to promote intercultural approaches (1). Intercultural health models such as complementary, traditional and integrative medicine (TCIM) contribute to self-determination by promoting self-care, empowerment, and a people-centered approach $(2,3)$.

\footnotetext{
* Official English translation from the original Spanish manuscript made by the Pan American Health Organization. In case of discrepancy, the original version shall prevail. Access to original manuscript: https://doi.org/10.26633/ RPSP.2020.143

1 School of Public Health, Boston University, Boston, United States of America.

2 Latin American and Caribbean Center on Health Sciences Information (BIREME), São Paulo, Brazil. $\square$ Carmen Mendes Abdala, abdalave@paho.org
}

The recognition of TCIM and their integration into health systems can help to reduce inequities and expand the options for interventions aimed at achieving comprehensive wellbeing. The Declaration of Alma-Ata (4) and, more recently, the Declaration of Astana (5) and the United Nations Political Declaration on Universal Health Coverage (6) all recognize that TCIM plays an important role in primary health care. In some cases, the diagnostic and therapeutic systems associated with TCIM are the only health services available, and they often reflect the local culture as well as community and 
individual preferences. TCIM has been recommended as a means of strengthening integrated people-centered health services $(3,7)$.

Access to information is a human right. Together with access to health information technology, it is also a key element in addressing health-related inequities $(8,9)$. In fact, barriers to information access at all levels are social determinants of health that carry over and affect other social determinants. Two of the 11 objectives of the Sustainable Health Agenda for the Americas 2018-2030 are directly related to accessing information for policy-setting, decision-making, and the generation and use of knowledge (10). Generating strategies that facilitate access to information is an important means of addressing inequities in health and guiding decision-making for action at several levels. Although TCIM-related scientific output has been growing, it continues to be quite limited $(11,12)$. In academic settings, this output is often published as gray literature, and in many cases is not available electronically. Access to information produced in the context of delivering health services is already limitedand even more so for indigenous populations and other ethnic groups.

In light of this shortcoming, strategic partners from several countries joined together to create a virtual health library (VHL) that offers perspectives on TCIM-based health interventions, facilitating both access to available scientific knowledge and the dissemination of information on political and legislative frameworks, technical documents, and experiences that support decision-making.

The present article summarizes the developments and progress achieved during the first three years of this initiative, from June 2017 until June 2020, with observations on the model implemented and its implications.

\section{BACKGROUND}

In June 2017, the Latin American and Caribbean Center on Health Sciences Information (BIREME), a specialized center of the Pan American Health Organization (PAHO), submitted a proposal at its Regional Meeting, "Advancing toward Universal Health, Contributions of Traditional and Complementary Medicine," to create a VHL specialized in TCIM, to be called the Virtual Health Library on Traditional, Complementary, and Integrative Medicine, or "VHL TCIM Americas" (13). This proposal, developed in collaboration with the PAHO/ WHO Representative Office in Nicaragua, was conceived as a technical cooperation response to the demand from Member States and other actors in the Region for reliable sources on TCIM, based on scientific data and verified technical information.

The VHL model is based on building networks for information management and knowledge exchange through cooperation with institutions and professionals on the production, mediation, and use of the health information.

To implement a VHL specialized in TCIM, it was necessary to form a regional network that would oversee the collaborative development and management of the various knowledge sources. This initiative, now known as the TCIM Americas Network, was created by a group of participants in the meeting mentioned above (14).

\section{DEVELOPMENT AND EVOLUTION OF VHL TCIM AMERICAS}

The process of creating VHL TCIM Americas got under way in July 2017. The first steps included diagnosing the needs, reviewing the terminology, developing a thematic structure, identifying information sources, formulating search strategies for the collection of data, generating content, establishing editorial committees, and defining the basic components around which the VHL content would be organized. This process was facilitated by the use of online collaboration tools and the application of information management methodologies developed by BIREME. The Director of PAHO officially inaugurated VHL TCIM Americas in March 2018 and it has been online since then with interfaces in Spanish, Portuguese, and English at http:/ / mtci.bvsalud.org.

VHL TCIM Americas is designed to meet the needs of health professionals and students, managers, researchers, TCIM practitioners, and the general public. The components of the portal, summarized in Table 1, are designed to facilitate understanding of the complex TCIM spectrum, ranging from health paradigms to therapeutic methods, and to offer summaries of scientifically verified data, information on national contexts, and TCIM-related legal and policy frameworks in the participating countries, among other areas of interest. In addition, a regional TCIM database was created to facilitate access to conventional and nonconventional literature not available in other repositories. This database, called MOSAICO (an abbreviation for its name in Spanish meaning "Traditional, Complementary, and Integrative Medicine and Health Models") indexes materials on TCIM from journals, books, monographs, theses, lectures, technical documents, legislation, and audiovisual educational resources produced in or about the Region of the Americas based on the selection criteria established. ${ }^{1}$ MOSAICO contains more than 1600 records, all with open access to the full-text articles. The majority of the records $(65 \%)$ correspond to gray literature. MOSAICO, as well as a number of other databases in the collection, can be accessed through the VHL interface (http:/ / mtci.bvsalud.org).

The collaborative support of the TCIM Americas Network has been essential to the development and evolution of VHL TCIM Americas. It serves as a "network of networks," with horizontal governance of production, coordination, and exchange mechanisms designed to promote research, generate knowledge, and develop theoretical approaches. One of its strengths is the diversity of participating actors from more than 15 countries, including officials from ministries of health and regulatory agencies, educators of health professionals, researchers, health service providers, and representatives of professional associations and nongovernmental organizations. ${ }^{2}$ This diverse participation has made it possible to meet the information needs for TCIM-related decision-making at several levels: health self-care, clinical practice, research, policy design, and standardization.

In line with the VHL TCIM Americas action plan, the Network is in the process of developing a number of products and

\footnotetext{
The document selection criteria for the MOSAICO database are available at: https://mtci.bvsalud.org/criterios-de-seleccion-de-documentos/

A complete description of the categories and the list of members of the TCIM Americas Network can be found at: http://mtci.bvsalud.org/acerca/
} 
TABLE 1. Components of the portal Virtual Health Library on Traditional, Complementary, and Integrative Medicine in the Americas (VHL TCIM Americas)

\begin{tabular}{|c|c|}
\hline Component & Brief description of content \\
\hline About & $\begin{array}{l}\text { Background, objectives, and description of the VHL TCIM Americas components and the collection, including the MOSAICO } \\
\text { database, communication materials, and information about the TCIM Americas Network }\end{array}$ \\
\hline Directory of institutions & $\begin{array}{l}\text { Country-by-country list of institutions engaged in TCIM leadership, regulation, education, research, promotion, service provision, } \\
\text { and coordination within health systems }\end{array}$ \\
\hline Regulations and Policies & $\begin{array}{l}\text { Information on legislation, policies, and models for coordinating TCIM in the health systems of countries of the Americas, including } \\
\text { the regulation of TCIM-related practices, practitioners, and products }\end{array}$ \\
\hline Traditional medicine in the Americas & $\begin{array}{l}\text { Information on indigenous peoples, Afro-descendants, and members of other ethnic groups in the Region of the Americas, } \\
\text { with descriptions of their ancestral knowledge, traditional medicines, health situation, characteristic health models, relevant } \\
\text { organizations, and other resources of interest }\end{array}$ \\
\hline Academic consortia & $\begin{array}{l}\text { Information about joint initiatives by academic institutions seeking to share their experiences and work collectively on TCIM-related } \\
\text { research projects-section currently being managed by the Brazilian Academic Consortium for Integrative Health (CABSIn) }\end{array}$ \\
\hline Health strengthening & Proposals, strategies, and health models aimed at strengthening and promoting health and self-care from the TCIM perspective \\
\hline Understanding TCIM & TCIM concepts, definitions, glossaries, and evidence maps, as well as thematic structure for organization of the databases \\
\hline Building research capacity & $\begin{array}{l}\text { Collection of educational resources, articles, reference documents, and other content aimed at building TCIM-related research } \\
\text { capacity }\end{array}$ \\
\hline Coordination of systems and services & $\begin{array}{l}\text { Information and reference documents on models proposed by countries in the Region for coordinating TCIM in health systems and } \\
\text { services }\end{array}$ \\
\hline Database searching & $\begin{array}{l}\text { Search box interface for accessing the VHL TCIM Americas collection, records from existing databases, and documents in the } \\
\text { MOSAICO database }\end{array}$ \\
\hline News and Calendar of events & Notices about reliable resources on the subject; news of pertinent national and international events \\
\hline
\end{tabular}

Source: VHL TCIM Americas Portal (http://mtci.bvsalud.org).

services. For example, virtual courses are being prepared with the aim of building research capacity in TCIM and intercultural competency for the coordination of TCIM within health systems. This initiative is being implemented in Peru as part of the work plan of the World Health Organization's Collaborating Center on Traditional and Complementary Medicine, which is part of the country's national social health insurance program (EsSalud). In addition, with funding from the Brazilian Ministry of Health, the Brazilian Academic Consortium for Integrative Health (CABSIn) has been working with BIREME on the development of TCIM evidence maps for areas including phytotherapy, traditional Chinese medicine, yoga, meditation, reflexology, ozone therapy, and shantala massageall published on VHL TCIM Americas. In response to the COVID-19 pandemic, an evidence map has been prepared to guide researchers and health professionals in science-based health decision-making.

VHL TCIM Americas has gained recognition by the international academic community (14). During the period April 2018-September 2020, users from 127 countries in all continents logged nearly 114000 sessions on its portal and consulted nearly 184000 pages (Figure 1).

\section{DISCUSSION}

Approximately $90 \%$ of the world's countries officially recognize the use of TCIM in their jurisdictions and, in particular, its contribution to the expansion of access to primary health care $(15,16)$. However, even though TCIM plays an important role in health services in many contexts, it has little presence in the communications media and scientific literature. For example, in the MEDLINE database, as of June 2020, only $4.6 \%$ of 28.5 million records were related to TCIM and less than $1 \%$ of the total were from Latin American journals. The proportion of
Latin American records on TCIM was even smaller. Similarly, in the Latin American and Caribbean Health Sciences Literature (LILACS) database, which is dedicated to giving visibility to Latin American and Caribbean scientific output, less than $5 \%$ of records are related to TCIM. ${ }^{3}$ Most of the academic and scientific output on TCIM in the countries of the Americas is in the form of gray literature, only available in isolated virtual repositories or non-virtual libraries. VHL TCIM Americas has afforded access to these documents by indexing them in MOSAICO, and it is also studying other nonconventional ways to bring attention to this documented traditional knowledge.

Still, VHL TCIM Americas is a work in progress. Meeting the objectives of every component in both the medium and long term will depend on many factors. Although much progress has been made, thanks essentially to volunteer work, execution of its activities and its proposed subprojects to update and generate content will depend on securing long-term financing, which until now it has been one of the limitations. Other challenges include the need for greater participation by organizations that work in areas of traditional medicine practiced by indigenous peoples, Afro-descendants, and other ethnic groups; expansion of the network to countries in the Region that have not yet joined it; and adding literature in French to the portal. While VHL TCIM Americas has users throughout the world, it needs to be promoted more actively with its target audience in the Americas.

VHL TCIM Americas is an innovative project, patterned after a replicable model developed by BIREME. There are no other similar undertakings in other regions of the world. ${ }^{4}$ Despite its

\footnotetext{
Figures based on searches of the VHL Regional Portal (http://bvsalud.org), accessed 12 June 2020.

4 A similar project is underway in India, called the Traditional Knowledge Digital Library (http://www.tkdl.res.in/). It is based on a different model that is more focused on the documentation of traditional knowledge as means of preventing biopiracy.
} 
FIGURE 1. Statistics on access to the Virtual Health Library on Traditional, Complementary, and Integrative Medicine (VHL TCIM Americas), ${ }^{a}$ April 2018-September 2020, by country of origin (total 127 countries)

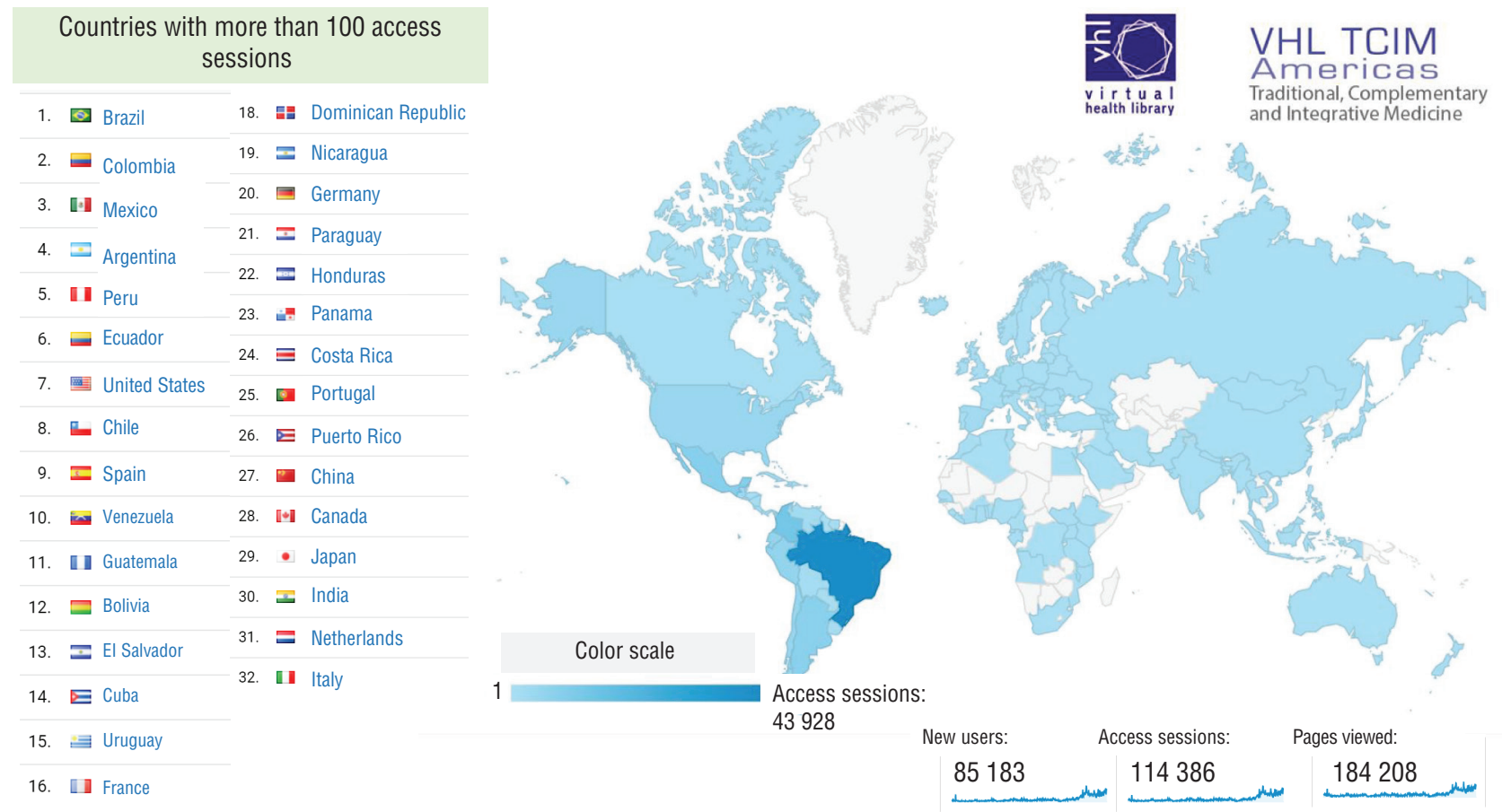

Source: Own preparation based on Google Analytics access data for VHL TCIM Americas as of 25 September 2020 a http://mtci.bvsalud.org

limitations and the challenges faced in its development, VHL TCIM Americas has made impressive achievements and has already become a resource for decision-making. In Brazil, for example, the National Health Council has formally recommended that federal, state, and municipal governments consult its evidence map on COVID-19 (17). In Chile, Colombia, and Curaçao, the TCIM Americas Network and VHL TCIM Americas have served as referents for the development of policies for the articulation of TCIM into their health systems. VHL TCIM Americas is aligned with regional policy instruments such as the Strategy for Universal Access to Health and Universal Health Coverage (18) and the PAHO Policy on Ethnicity and Health (1), as well as the WHO Traditional Medicine Strategy 2014-2023 (3), and it is one of the tools for their implementation.

Although most Latin American countries recognize their multiethnic nature and the importance of intercultural approaches, there are still major challenges to eliminating inequities (19). It is essential to move forward in the democratization of knowledge, including multiethnic and multidisciplinary constructs (20). The promotion of traditional knowledge and scientific output also depends on how information is produced and being able to overcome language barriers. The criteria for the publication of manuscripts in the principal scientific journals tend to marginalize studies that use models or types of knowledge that do not conform to the Eurocentric "western" model. The connection between colonialism and health inequities involves, among other barriers, difficult access to knowledge about traditional medicine (21).

Knowledge generated according to the conventional parameters of science is essential, but it is not the only knowledge that exists. Western medicine itself is a sociocultural system with its own values and beliefs. Lack of awareness of different cultures is the greatest barrier to progress in achieving the highest possible standards of health worldwide (22). To address the challenges faced by health systems as they strive to meet the changing needs of their populations, it will be necessary to take into account culture, knowledge, and practices that have been marginalized until now. Sites like VHL TCIM Americas, which give visibility to other forms of knowledge, make it possible to share this knowledge and play a key role in guaranteeing the right to access information, eliminating the inequities that impact health, and achieving a state of complete physical, mental and social well-being for all people.

Author contributions. DFGP conceived the article and wrote the first draft; CVMA contributed to analysis of the data; and NSAM helped to draft the section on development of the project. All the authors collaborated on subsequent drafts and discussion, and they all reviewed and approved the final version.

Acknowledgments. The authors wish to thank the entire TCIM Americas Network team, without whose collaboration this project would not have been possible.

Conflict of interests. All the authors are part of the Network of Traditional, Complementary and Integrative Medicine of the Americas (TCIM Americas Network) and declare that they do not have any conflict of interests.

Disclaimer. Authors hold sole responsibility for the views expressed in the manuscript, which may not necessarily reflect the opinion or policy of the RPSP/PAHPH or the Pan American Health Organization (PAHO). 


\section{REFERENCES}

1. Pan American Health Organization. Policy on ethnicity and health [Internet]. 29th Pan American Sanitary Conference, 69th Session of the Regional Committee of WHO for the Americas. Washington, DC: PAHO; 2017 (Document CSP29/7, Rev. 1) [accessed 20 May 2020]. Available from: https://www.paho.org/hq/index. php?option=com_docman\&view=download\&category_slug=29en-9249\&alias=42294-csp29-r3-e-294\&Itemid=270\&lang=en

2. Maizes V, Rakel D, Niemiec C. Integrative medicine and patient-centered care. Explor J Sci Heal [Internet]. 2009;5(5):277-89 [accessed 20 May 2020]. Available from: http://dx.doi.org/10.1016/j. explore.2009.06.008

3. World Health Organization. WHO Traditional medicine strategy 2014-2023 [Internet]. Geneva: WHO 2013 [accessed 20 May 2020]. Available from: https://www.who.int/publications/i/ item/9789241506096

4. International Conference on Primary Health Care. Declaration of Alma-Ata. WHO Chron [Internet]. 1978;32(11):428-30 [accessed 20 May 2020]. Available from: http://www.who.int/publications/ almaata_declaration_en.pdf

5. Global Conference on Primary Health Care. Declaration of Astana [Internet]. Astana: World Health Organization, United Nations Children's Fund; 2018 [accessed 20 May 2020]. Available from: https:// www.who.int/docs/default-source/primary-health/declaration/ gcphc-declaration.pdf

6. United Nations. Political Declaration of the High-level Meeting on Universal Health Coverage. Universal health coverage: moving together to build a healthier world [Internet]. New York: UN; 2019 [accessed 20 May 2020]. Available from: https:// www.un.org/pga/73/wp-content/uploads/sites/53/2019/07/ FINAL-draft-UHC-Political-Declaration.pdf

7. World Health Organization. Strengthening integrated, people-centred health services [Internet]. 69th World Health Assembly. Geneva: WHO; 2016 (Document WHA69.24) [accessed 20 May 2020]. Available from: https://apps.who.int/gb/ebwha/pdf_files/WHA69/ A69_R24-en.pdf

8. Brennan PF. The role of the National Library of Medicine in advancing the science of health disparities. Med Care. 2019;57(6): S104-5.

9. Zhang X, Hailu B, Tabor DC, Gold R, Sayre MH, Sim I, et al. Role of health information technology in addressing health disparities: Patient, clinician, and system perspectives. Med Care. 2019;57(6):S115-20.

10. Pan American Health Organization. Sustainable Health Agenda for the Americas 2018-2030: A call to action for health and well-being in the [Internet]. 29th Pan American Sanitary Conference, 69th Session of the Regional Committee of WHO for the Americas. Washington, DC: PAHO; 2017 (Document CSP29/6, Rev. 3) [accessed 20 May 2020]. Available from: https://www.paho.org/hq/index. php?option=com_docman\&view $=$ download\&category_slug $=29-$ en-9249\&alias=41946-csp29-6-e-946\&Itemid=270\&lang=en

11. Langdon EJ, Garnelo L. Articulación entre servicios de salud y "medicina indígena": Reflexiones antropológicas sobre política y realidad en Brasil. Salud Colect. 2017;13(3):457-70.

12. Fu JY, Zhang X, Zhao YH, Huang MH, Chen DZ. Bibliometric analysis of complementary and alternative medicine research over three decades. Scientometrics. 2011;88(2):617-26.
13. Pan American Health Organization. Participants from 21 countries of the Region propose increased collaboration in traditional and complementary medicines to move toward universal health [Internet]. Washington, DC: PAHO; 2017 [accessed 20 May 2020]. Available from: https://www.paho.org/hq/index.php?option=com_content \&view=article\&id=13423:participants-from-21-countries-of-the-region-propos-increased-collaboration-in-tradiciontal-medicine-universal-health\&Itemid=39594\&lang $=$ en

14. Weeks J. Infrastructure to spur inclusion of traditional, complementary, and integrative medicine: The TCIM Americas Network model inside the Pan American Health Organization. J Altern Complement Med. 2020;26(2):82-4.

15. World Health Organization. WHO global report on traditional and complementary medicine 2019 [Internet]. Geneva: WHO; 2019 [accessed 20 May 2020]. Available from: https:/ / apps.who.int/iris/ handle/10665/312342

16. World Health Organization. WHO Interregional Workshop on the Use of Traditional Medicine in Primary Health Care [Internet]. Geneva: WHO; 2007 [accessed 20 May 2020]. Available from: https://www. who.int/medicines/areas/traditional/mongolia_reporttrm/en/

17. Brasil, República Federativa. Conselho Nacional de Saúde. Recomendação No. 041. Recomenda ações sobre o uso das práticas integrativas e complementares durante a pandemia da Covid-19 [Internet]. Brasília: Ministério da Saúde, Conselho Nacional de Saúde; 2020 [accessed 20 May 2020]. Available from: https://conselho.saude.gov.br/images/Recomendacoes/2020/Reco041.pdf

18. Pan American Health Organization. Strategy for universal access to health and universal health coverage [Internet]. 53rd Directing Council of PAHO, 66th Session of the Regional Committee of WHO for the Americas. Washington, DC: PAHO; 2014 (Document CD53/5 Rev. 2) [accessed 20 May 2020]. Available from: https:/ /www.paho. org/hq/dmdocuments/2014/cd53-5-e.pdf

19. Guzmán-Rosas CS, Kleiche-Dray M. La inclusión del conocimiento tradicional indígena en las políticas públicas del Estado mexicano [Internet]. Gest Polit Publica. 2017;XXVI(2):297-339 [accessed 20 May 2020]. Available from: http://www.scielo.org.mx/pdf/gpp/ v26n2/1405-1079-gpp-26-02-00297.pdf

20. Kabad JF, Pontes AL de M, Monteiro S. Relações entre produção científica e políticas públicas: o caso da área da saúde dos povos indígenas no campo da saúde coletiva. Cien Saude Colet. 2020;25(5):1653-66

21. Pan American Health Organization. Just societies: Health equity and dignified lives. Report of the Commission of the Pan American Health Organization on Equity and Health Inequalities in the Americas. Washington, DC: PAHO; 2019.

22. Napier AD, Ancarno C, Butler B, Calabrese J, Chater A, Chatterjee $\mathrm{H}$, et al. Culture and health. Lancet [Internet]. 2014;384(9954):160739 [accessed 20 May 2020]. Available from: https://www.thelancet. $\mathrm{com} /$ commissions/neglect-of-culture-in-health

Manuscript (original in Spanish) received on 16 June 2020. Accepted for publication, following review, on 30 July 2020. 


\section{Equidad, abordajes interculturales y acceso a la información sobre las medicinas tradicionales, complementarias e integrativas en las Américas}

RESUMEN El acceso a la información y los abordajes interculturales en el ámbito de la salud son esenciales para la eliminación de inequidades en el acceso a los servicios de salud y la atención sanitaria. Los modelos interculturales, como las medicinas tradicionales, complementarias e integrativas (MTCI) son una parte importante del cuidado de la salud en la mayoría de los países y frecuentemente contribuyen a ampliar el acceso a la atención primaria de salud. A pesar del reconocimiento legal y de la existencia de políticas para la integración de las $\mathrm{MTCl}$ en los sistemas de salud, aún se subestima su contribución a la salud, el bienestar y la atención de la salud centrada en las personas para alcanzar la salud universal. En este artículo se presentan los avances (2017-2020) alcanzados por la Biblioteca Virtual en Salud especializada en las MTCI (BVS MTCI Américas), iniciativa creada como herramienta para disminuir las brechas en la producción y el acceso a la información validada sobre las $\mathrm{MTCl}$. Mediante el trabajo colaborativo en red, la BVS MTCI Américas contribuye a la democratización de la salud, el acceso a datos científicos verificados disponibles, la visibilización de conocimientos no convencionales, el fortalecimiento de capacidades de investigación y el intercambio de experiencias para la toma informada de decisiones.

Palabras clave Medicina tradicional; terapias complementarias; atención integral de salud; equidad en salud; acceso a la información; bibliotecas digitales.

\section{Equidade, abordagens interculturais e acesso a informações sobre medicinas tradicionais, complementares e integrativas nas Américas}

RESUMO O acesso à informação e as abordagens interculturais no setor da saúde são essenciais para eliminar as desigualdades no acesso aos serviços de saúde. Os modelos interculturais, como as medicinas tradicionais, complementares e integrativas (MTCl), são uma parte importante da atenção à saúde na maioria dos países e frequentemente contribuem para ampliar o acesso à atenção primária. Apesar do reconhecimento legal e da existência de políticas para a integração das MTCI nos sistemas de saúde, a sua contribuição para a saúde, o bem-estar e a atenção centrada nas pessoas para alcançar a saúde universal ainda é subestimada. Este artigo apresenta o progresso (de 2017 a 2020) alcançado pela Biblioteca Virtual em Saúde especializada em MTCI (BVS MTCI Américas), uma iniciativa criada como ferramenta para reduzir as disparidades na produção e no acesso a informações validadas sobre as MTCl. Realizando um trabalho colaborativo em rede, a BVS MTCl Américas contribui para a democratização da saúde, o acesso a dados científicos verificados, a visibilidade dos conhecimentos não convencionais, o fortalecimento das capacidades de pesquisa e a troca de experiências para a tomada de decisões bem informada.

Palavras-chave Medicina tradicional; terapias complementares; assistência integral à saúde; equidade em saúde; acesso à informação; bibliotecas digitais. 